\title{
Effective Overall Heat Transfer Coefficient Solver in a Triple Concentric-Tube Heat Exchanger
}

\begin{abstract}
SINZIANA RADULESCU, LOREDANA IRENA NEGOITA*, ION ONUTU
Petroleum-Gas University of Ploiesti, 39 Bucuresti Blv., 100680, Ploiesti, Romania

A relation for calculation of the effective overall heat transfer coefficient in a triple concentric-tube heat exchanger is proposed. The relation of the effective overall heat transfer coefficient is obtained based on total thermal resistance and it is applied within a case study for thermal analysis of two triple concentrictube heat exchangers with different geometries, hot fluids and operating conditions. Through case study it is found that the values of effective overall heat transfer coefficient can be obtained with acceptable errors, up to $3 \%$ for both heat exchangers.
\end{abstract}

Keywords: thermal resistance, overall heat transfer coefficient, triple concentric-tube heat exchanger

In a triple concentric-tube heat exchanger the fluid to be cooled or heated flows through the inner annulus formed betw een the inner tube and the intermediate one, and the heating or the cooling medium flows in the inner tube and the outer annulus formed between the intermediate tube and the outer tube. When the hot fluid flows through the inner annulus, it transfers heat in two opposite directions. One heat transfer direction is that of the cold fluid that flows through the inner tube (fluid C1), for which the overall heat transfer coefficient, $U_{1}$ is as defined. The other heat transfer direction is of the cold fluid that flows through the outer annulus (fluid C2), for which the overall heat transfer coefficient, $U_{2}$ is as defined. Moreover, an effective overall heat transfer coefficient $U$, which represents the total heat transfer occurring in the triple concentric-tube heat exchanger, can be calculated. When knowing $U_{\text {ef }}$ the design calculation can quickly lead to an effective length, and, as a consequence, the performance of a triple concentric-tube heat exchanger can be estimated more easily when compared to other types of heat exchanger. Many researchers, such as Zurit [1], Satyanarayana et al. [2], Unal [3], Sahoo etal. [4], Batmaz [5], Peigné et al. [6], Boultif and Bougriou [7] and Touatit and Bougriou [8] have published the equations of the overall heat transfer coefficients $\left(U_{1}\right.$ and $\left.U_{2}\right)$ based on the series thermal resistances or the expressions analogous to Newton's law of cooling, in order to design and evaluate the performance of a triple concentric-tube heat exchanger. Instead, how the calculation of the effective overall heat transfer is not reported to the best of its knowledge. The aim of this paper is to present a simple and accurate relation for the calculation of effective overall heat transfer coefficient in a triple concentric-tube heat exchanger, based on the total thermal resistance. Moreover, the calculus of the local heat transfer coefficients and overall heat transfer coefficients is approached. The relation presented in this paper for the effective overall heat transfer coefficient is applied within a case study for thermal analysis of two triple concentrictube heat exchanges with different geometries and operating conditions. One heat exchanger was designed in our laboratory; it is experimental and was used to cool oil with water. The other heat exchanger was designed by Zuritz [1] and used to cool liquid food with water. For both heat exchangers, the values of $U_{1}, U_{2}$ and $U_{\text {f }}$ obtained based on the equations of thermal resistances, are compared with those got from expressions analogous to Newton's law of cooling.

\footnotetext{
* email irena.negoita@gmail.com
}

\section{The calculation of $U_{1}, U_{2}$ and $U_{\text {ef }}$ : Mathematical formulation}

In this section presents the calculation of $U_{1}, U_{2}$ and $U$ in a triple concentric-tube heat exchanger, where hot fluid flows through the inner annulus and cold fluid flows through the inner tube (fluid C1) and outer annulus (fluid C2) under counter-current arrangement. In order to perform the heat transfer analysis of the heat exchanger, the following assumptions are considered: the system is at steady state; fluid properties are constants; single phase flow conditions; heat exchanger is insulated and there are no heat losses. As shown in figure, the total thermal resistance on apparatus consists of: the convective resistance on the inner surface of inner tube (R1), the conduction resistance of the inner tube wall (R2), the convective resistance on the outer surface of inner tube (R3), the convective resistance on the inner surface of intermediate tube (R4), the conduction resistance of the intermediate tube wall (R5) and the convective resistance on the outer surface of intermediate tube (R6). The thermal resistances R1, R2, $R 3$ series which defines $U_{1}$ occur in parallel with the thermal resistances R4, R5, R6 series which defines $U_{2}$. The effective overall heat transfer coefficient is related to the total effect of the thermal resistances. The fouling resistance has not been considered.

The expressions of $U_{1}, U_{2}$ and $U_{\text {ef }}$ can be obtained based on thermal resistances, by means of an analogy with the electric resistances expressions considering convection and conduction in cylindrical coordinates. For the thermal resistances series and expressions analogous to Newton's law of cooling, the expressions of the heat flow rates for the cold fluid that flows through the inner tube $\left(Q_{1}\right)$ and for the cold fluid that flows through the outer annulus $\left(Q_{2}\right)$ are:

$$
\begin{gathered}
Q_{1}=\frac{\Delta t_{1}}{\sum R_{t 1}}=h_{2 o} A_{1 o}\left(t_{H}-t_{w 1 o}\right) \\
Q_{2}=\frac{\Delta t_{2}}{\sum R_{t 2}}=h_{2 i} A_{2 i}\left(t_{H}-t_{w 2 i}\right)
\end{gathered}
$$

In equations (1), $R_{\text {t }}$ is the thermal resistance series corresponding to $Q_{1}$, thus

$R_{t 1}=R 1+R 2+R 3=\frac{1}{h_{1} A_{1 i}}+\frac{1}{2 \pi k} \ln \frac{d_{10}}{d_{1 i}}+\frac{1}{h_{20} A_{10}}$ (3)

where $t_{H}$ is the average temperatures of the hot fluid, $t_{w 70}$ is the outside (wall) surface temperature of the inner tuibe, 


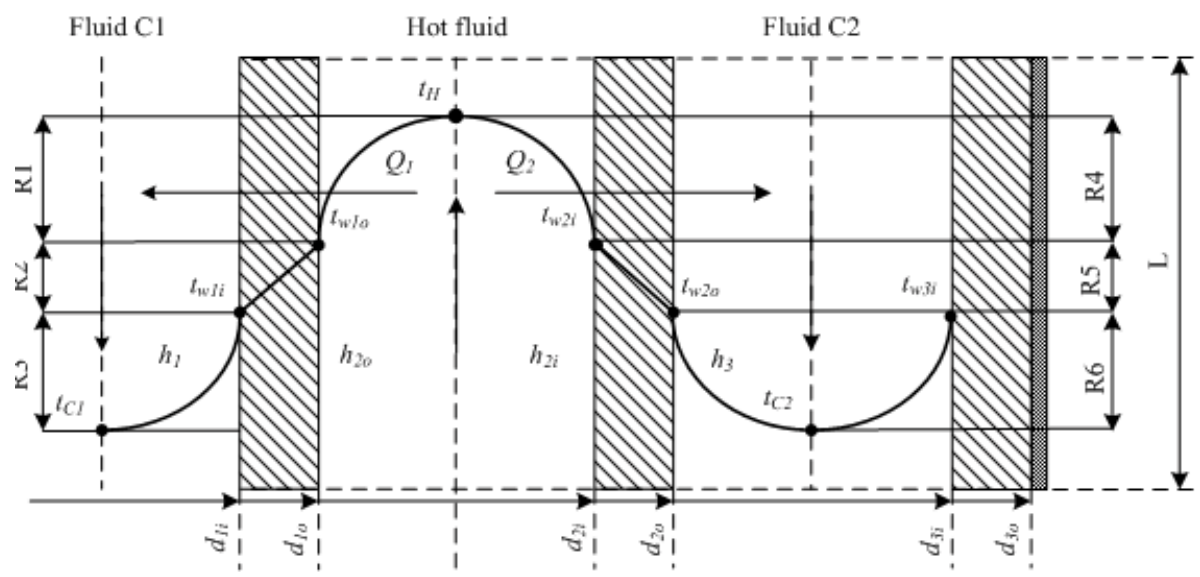

Fig. 1 Thermal resistances in a triple concentric-tube heat exchanger

$h_{1}$ and $h_{20}$ are the convective heat transfer coefficients for the inside and outside surface of the inner tube, $d_{1 i}$ and $d_{10}$ are the inner and outer diameters of the inner tube, $k$ is the thermal conductivity of the metal tube, $A_{1 j}$ and $A_{10}$ are the inside and outside areas of the inner tube and $k$ is the thermal conductivity of the metal tube.

In equation (2), $R_{t 2}$ is the thermal resistance series corresponding to $Q_{2^{\prime}}$ expressed as follows

$$
R_{t 2}=R 4+R 5+R 6=\frac{1}{h_{2 i} A_{2 i}}+\frac{1}{2 \pi k} \ln \frac{d_{20}}{d_{2 i}}+\frac{1}{h_{3} A_{20}}
$$

where $t_{\text {wi }}$ is the inside surface temperature of the intermediate tube, $h_{2 i}$ and $h_{3}$ are the convective heat transfer coefficients for the inside and outside surface of the intermediate tube, $d_{2}$ and $d_{2}$ are the inner and outer diameters of the intermediate tube, $A_{2 i}$ and $A_{20}$ are the inside and outside areas of the intermediate tube.

Moreover, $Q_{1}^{0}$ and $Q_{2}$ can be written as:

$$
\begin{aligned}
& Q_{1}=\frac{\Delta t_{1}}{A_{10} \sum R_{t 1}}=U_{1} \cdot A_{10} \cdot \Delta t_{1} \\
& Q_{2}=\frac{\Delta t_{2}}{A_{20} \sum R_{t 2}}=U_{2} \cdot A_{20} \cdot \Delta t_{2}
\end{aligned}
$$

From the equations (3) and (5), there was obtained the following expression of $U_{1}$ for the outside area of the inner tube:

$$
U_{1}=\frac{1}{\frac{d_{10}}{h_{1} d_{1 i}}+\frac{d_{10}}{2 \pi k} \ln \frac{d_{10}}{d_{1 i}}+\frac{1}{h_{2 i}}}
$$

Based on equations (4) and (6), the following expression of $U_{2}$ for the outside area of the intermediate tube was formulated:

$$
U_{2}=\frac{1}{\frac{d_{20}}{h_{20} d_{2 i}}+\frac{d_{20}}{2 \pi k} \ln \frac{d_{20}}{d_{2 i}}+\frac{1}{h_{3}}}
$$

For the parallel heat transfer in the heat exchanger and the total heat transfer area which equals the sum of $A_{10}$ and $A_{20^{\prime}}$ the expressions of the heat flow rate based on the hot fluid $(Q)$ can be written as:

$$
Q=\frac{\Delta t}{\frac{1}{\sum \frac{1}{R_{t}}}}=\frac{\Delta t}{\frac{1}{\frac{1}{R_{t 1}}+\frac{1}{R_{t 2}}}}=\frac{\Delta t}{\left(A_{10}+A_{2 o}\right) \frac{1}{\frac{1}{R_{t 1}}+\frac{1}{R_{t 2}}}}=U_{e f}\left(A_{1 o}+A_{2 o}\right) \Delta t
$$

In equation (9) $R_{t}$ is the total thermal resistance for the parallel heat transfer corresponding to $Q$ and $\Delta t=t_{H}-t_{C}$. Furthermore, by replacing $R_{t 7}$ and $R_{t 2}$ in equation (9) with their expressions by equations (3) and (4) and considering a total (effective) length of the heat exchanger, can be obtained the following expression of $U_{e f}$;

$$
U_{e f}=\frac{\frac{1}{h_{1} d_{1 i}}+\frac{1}{2 \pi k} \ln \frac{d_{10}}{d_{1 i}}+\frac{1}{h_{20} d_{10}}+\frac{1}{h_{2 i} d_{2 i}}+\frac{1}{2 \pi k} \ln \frac{d_{20}}{d_{2 i}}+\frac{1}{h_{3} d_{20}}}{\left(\frac{1}{h_{1} d_{1 i}}+\frac{1}{2 \pi k} \ln \frac{d_{10}}{d_{1 i}}+\frac{1}{h_{20} d_{10}}\right)\left(\frac{1}{h_{2 i} d_{2 i}}+\frac{1}{2 \pi k} \ln \frac{d_{20}}{d_{2 i}}+\frac{1}{h_{3} d_{20}}\right)\left(d_{10}+d_{20}\right)}
$$

Other equations used for estimating $U_{1}, U_{2}$ and $U_{\text {ef }}$ are the following: 


$$
\begin{aligned}
& Q_{1}=m_{C 1} c_{p C 1}\left(t_{C 1 \mathrm{out}}-t_{C 1 \text { in }}\right)=U_{1} \cdot A_{10} \cdot \Delta t_{m l 1} \\
& Q_{2}=m_{C 2} c_{p C 2}\left(t_{C 2 \mathrm{out}}-t_{C 2 \text { in }}\right)=U_{2} \cdot A_{2 o} \cdot \Delta t_{m l 2} \\
& Q=Q_{1}+Q_{2}=m_{H} c_{p H}\left(t_{\text {Hin }}-t_{\text {Hout }}\right)=U_{\text {ef }}\left(A_{1 o}+A_{2 o}\right) \Delta t_{m l}
\end{aligned}
$$

where $m_{c 1^{\prime}} m_{c z^{\prime}} m_{H^{\prime}}$ are the mass flow rates, $c_{p q_{1}^{\prime}} c_{p c 2^{\prime}} c_{p H}$ are the specific heats, $t_{\text {clout }} t_{c 20 y^{\prime}} t_{\text {Hout }}$ are the outlet temperatures and $t_{c \text { in, }} t_{c \text { in }}$, $t_{H \text { in }}$ are the inlet temperatures, all for both cold fluids and hot fluid, and $\Delta t_{l m 1^{\prime}} \Delta t_{l m 2}$ and $\Delta t_{l m}$ are the logarithmic mean temperature differences. For the counter-current flow arrangement, $\Delta t_{l m 1^{1}} \Delta t_{l m 2}$ and $\Delta t_{l m}$ can be expressed as Batmaz [5].

\section{Case study}

Our case study aims to evaluate the accuracy of the relation (10) proposed to calculate $U_{\text {ef }}$ in a triple concentrictube heat exchanger. Therefore, we carried out thermal analysis in two distinct geometric and operational heat exchangers with triple concentric-tube. One heat exchanger is experimental and the other one was designed by Zuritz [1]. The experimental heat exchanger is operated under laboratory conditions in order to cool oil, and more details about experimental setup can be found in our previous researches [ 9 - 11]. In the heat exchanger, a flow rate of $103 \mathrm{~kg} / \mathrm{h}$ oil is cooled in the inner annulus from 80.5 to $70.2^{\circ} \mathrm{C}$ with two cold water streams. Cold water enters the heat exchanger with $10.8^{\circ} \mathrm{C}$ and at the output of the heat exchanger it has $12.5^{\circ} \mathrm{C}$ for the inner tube and $13.9^{\circ} \mathrm{C}$, respectively for the outer annulus. The mass flow rates for cold water streams are $180 \mathrm{~kg} / \mathrm{h}$ for fluid $\mathrm{Cl}$ and $110 \mathrm{~kg} / \mathrm{h}$ for fluid C2. The uncertainty of the temperature measurements is $\pm 0.1^{\circ} \mathrm{C}$. The physical properties of oil at an average temperature of $75.4^{\circ} \mathrm{C}$ are the following: density $859 \mathrm{~kg} / \mathrm{m}^{3}$, specific heat $2061 \mathrm{~J} /\left(\mathrm{kg} .{ }^{\circ} \mathrm{C}\right)$, thermal conductivity $0.118 \mathrm{~W} /(\mathrm{m} . \mathrm{C})$ and dynamic viscosity 0.0089 $\mathrm{kg} /(\mathrm{m} . \mathrm{s})$. The other heat exchanger was designed by Zuritz for cooling a liquid food with water and more details about his study can be found in [1]. For both heat exchangers, $U_{1}$ $U$, and $U_{\text {ef }}$ were calculated by using equations (7), (8) and (10), equations based on thermal resistances. Then, the values were compared with those obtained from the expressions analogous to Newton's law of cooling, namely equations (11) - (13).

Local heat transfer coefficients were calculated by using the Nusselt number $(\mathrm{Nu})$ correlations found in literature and recommended for the range of Reynolds number $(R e)$ and other particular conditions of the flow.

$$
N u=\frac{h \cdot l_{c}}{k}
$$

Zuritz [1] calculated $h$ by using Sieder and Tate correlation for the turbulent flow regime and $h_{20}, h_{2 i}$ and $h_{3}$ by using Monrad and Pelton correlation for the turbulent flow regime. Zurit [1] used the equivalentheated diameter as the characteristic length $(I)$ when he calculated Reand Nu numbers into the annuli, although several authors [ 12 ,

\begin{tabular}{|c|c|c|c|}
\hline Parameters Flow space & Inner tube & Inner annulus & Outer annulus \\
\hline \multicolumn{4}{|c|}{ The experimental heat exchanger } \\
\hline$Q, W$ & 356 & 753 & 397 \\
\hline $\mathrm{I}_{\mathrm{c}} \mathrm{m}$ & 0.012 & 0.012 & 0.012 \\
\hline $\operatorname{Re}$ & 4236 & 128 & 466 \\
\hline $\mathrm{Nu}$ & 39.2 & - & 5.9 \\
\hline $\mathrm{h}, \mathrm{W} /\left(\mathrm{m}^{2 .} \cdot{ }^{\circ} \mathrm{C}\right)$ & 1889 & $h_{21}=114$, eq. $(1) ; h_{20}=113$, eq. (2) & 286 \\
\hline $\mathrm{U}_{1}$, eq. $(7), \mathrm{W} /\left(\mathrm{m}^{2} \cdot{ }^{\circ} \mathrm{C}\right)$ & 106.52 & - & - \\
\hline $\mathrm{U}_{2}$, eq. (8), W/(m $\left.\mathrm{m}^{2} \cdot{ }^{\circ} \mathrm{C}\right)$ & - & - & 76.55 \\
\hline$\Delta \mathrm{t}_{m l_{9}}{ }^{\circ} \mathrm{C}$ & 63.6 & 63.3 & 62.9 \\
\hline $\mathrm{U}_{1}$, eq. $(11), \mathrm{W} /\left(\mathrm{m}^{2} \cdot{ }^{\circ} \mathrm{C}\right)$ & 106.66 & & \\
\hline $\mathrm{U}_{2}$, eq. $(12), \mathrm{W} /\left(\mathrm{m}^{2 .}{ }^{\circ} \mathrm{C}\right)$ & - & - & 76.62 \\
\hline $\mathrm{U}_{\text {of, }}$ eq. $(10), \mathrm{W} /\left(\mathrm{m}^{2 .}{ }^{\circ} \mathrm{C}\right)$ & \multicolumn{3}{|c|}{86.54} \\
\hline $\mathrm{U}_{\text {of, }} \mathrm{eq} \cdot(13), \mathrm{W} /\left(\mathrm{m}^{2 \cdot{ }^{\circ} \mathrm{C}}\right)$ & \multicolumn{3}{|c|}{88.30} \\
\hline Error, $\mathrm{U}_{1}, \%$ & \multicolumn{3}{|c|}{-0.13} \\
\hline Error, $\mathrm{U}_{2}, \%$ & \multicolumn{3}{|c|}{-0.09} \\
\hline Error, $\mathrm{U}_{\text {af }}, \%$ & \multicolumn{3}{|c|}{-2.03} \\
\hline \multicolumn{4}{|c|}{ The heat exchanger designed by Zuritz [1] } \\
\hline$Q^{*}, W$ & 51990 & 111120 & 59130 \\
\hline $\mathrm{l}_{\mathrm{c}}^{8}, \mathrm{~m}$ & 0.060 & $\mathrm{~d}_{20}=0.0993 ; \mathrm{d}_{2 \mathrm{i}}=0.0670$ & $\mathrm{~d}_{\mathrm{t3i}}=0.0927$ \\
\hline $\mathrm{Re}^{*}$ & 29470 & 7040 (with $\mathrm{d}_{2_{0}}$ ); 4750 (with $\mathrm{d}_{22 \mathrm{i}}$ ) & 19080 \\
\hline $\mathrm{Nu}^{*}$ & 165.60 & 67.5 (with $\mathrm{d}_{22_{0}}$ ); 49.3 (with $\mathrm{d}_{2 \mathrm{i}}$ ) & 117.70 \\
\hline $\mathrm{h}^{8}, \mathrm{~W} /\left(\mathrm{m}^{2} \cdot{ }^{\circ} \mathrm{C}\right)$ & 1240 & $\begin{array}{l}h_{20}=300\left(\text { with } d_{220}\right) \\
h_{2 i}=270\left(\text { with } d_{22_{i}}\right)\end{array}$ & 560 \\
\hline $\mathrm{U}_{1,}$ eq. $(7), \mathrm{W} /\left(\mathrm{m}^{2} \cdot{ }^{\circ} \mathrm{C}\right)$ & 248.34 & 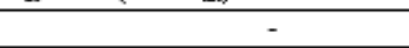 & - \\
\hline $\mathrm{U}_{2}$, eq. $(8), \mathrm{W} /\left(\mathrm{m}^{2 .} \cdot{ }^{\circ} \mathrm{C}\right)$ & - & - & 113.57 \\
\hline$\Delta \mathrm{tm}_{\mathrm{ml}},{ }^{\circ} \mathrm{C}$ & 31.7 & 28.8 & 25.8 \\
\hline $\mathrm{U}_{1}$, eq. $(11), \mathrm{W} /\left(\mathrm{m}^{2 \cdot} \cdot{ }^{\circ} \mathrm{C}\right)$ & 222.51 & - & - \\
\hline $\mathrm{U}_{2}$, eq. $(12), \mathrm{W} /\left(\mathrm{m}^{2} \cdot{ }^{\circ} \mathrm{C}\right)$ & - & - & 114.32 \\
\hline $\mathrm{U}_{\mathrm{of}, \mathrm{eq} .}(10), \mathrm{W} /\left(\mathrm{m}^{2 .} \cdot{ }^{\circ} \mathrm{C}\right)$ & \multicolumn{3}{|c|}{167.09} \\
\hline 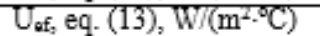 & \multicolumn{3}{|c|}{171.59} \\
\hline Error, $\mathrm{U}_{1}, \%$ & \multicolumn{3}{|c|}{10.40} \\
\hline Error, $\mathrm{U}_{2}, \%$ & \multicolumn{3}{|c|}{-0.13} \\
\hline Error, $\mathrm{U}_{\text {of }}, \%$ & \multicolumn{3}{|c|}{-2.69} \\
\hline
\end{tabular}
13] recommend the use of the equivalent hydraulic

Table 1

MAIN RESULTS OBTAINED FOR THE HEAT EXCHANGERS

${ }^{8}$ The values calculated by Zuritz [1] 
diameter in the $\mathrm{Nu}$ and Re numbers or the equivalent hydraulic diameter in Renumber and the equivalent heated diameter in Nu number.

For the experimental heat exchanger, the heat transfer coefficient for the inside surface of the inner tube was calculated from Gnielinsky correlation for the transition flow regime $[12,13]$ :

$$
N u=\frac{\left(\frac{f}{8}\right)(R e-1000) \operatorname{Pr}}{1+12.7 \sqrt{\left(\frac{f}{8}\right)}\left(\operatorname{Pr}^{\frac{2}{3}}-1\right)}\left[1+\left(\frac{d}{L}\right)^{\frac{2}{3}}\right]
$$

As opposed to Zuritz [1], for the experimental heat exchanger we did not use a Nusselt number correlation for compute heat transfer coefficient in the inner annulus and also, we did not use the equivalent heated diameter as the characteristic length in the outer annulus. Our option is due to the fact that in the experimental heat exchanger there are small flow sections through the annuli spaces, so that the use of equivalent heated diameter is not recommended. Also, according to the experimental data for the flow through the annuli, there is no significant variation of the fluid's physical properties with temperature. Thus, the heat transfer coefficient in the outer annulus space, for the laminar flow regime was calculated based on the following correlation [13]:

$$
N u=3.657+\frac{0.0668\left(\frac{d \cdot R e \cdot P r}{L}\right)^{\frac{1}{3}}}{0.04+\left(\frac{d \cdot R e \cdot P r}{L}\right)^{-\frac{2}{3}}}
$$

In this case, if $h_{1}$ and $h_{3}$ are known, it is possible to calculate $h_{2 i}$ and $h_{20}^{1}$ in the inner annulus by using the expressions analogous to Newton's law of cooling (equations (1) and (2)).

The results obtained for the two triple concentric-tube heat exchangers are presented in table 1 .

As shown in the table, the values of errors for $U_{1}, U_{2}$ and $U_{\text {ef }}$ are smaller for the experimental heat exchanger than for the heat exchanger designed by Zuritz. As these values are not so large, they may be considered acceptable, as well as the relation (10) for $U_{e f}$ presented in this paper.

\section{Conclusions}

A methodology for the calculation of effective overall heat transfer coefficient in a triple concentric-tube heat exchanger based on total thermal resistances have been developed in this paper. The results of the case study concerning the heat transfer analysis for two different triple concentric-tube heat exchangers proved that the effective overall heat transfer coefficient can be calculated with acceptable errors. Therefore, it can be concluded that the relation established for $U_{\text {ef }}$ (equation (10)) can be considered useful, both in the design and in the control of the operation in triple concentric-tube heat exchangers.

\section{Nomenclature}

A - heat transfer area $(A=\pi \mathrm{dL}), \mathrm{m}^{2} ; \mathrm{c}_{\mathrm{p}}$-specific heat, J $(/ \mathrm{kg} . \mathrm{C})$; $\mathrm{d}$-diameter, $\mathrm{m}$; $f$-Darcy friction factor; $\mathrm{h}$-convective heat transfer coefficient, $\mathrm{W} /\left(\mathrm{m}^{2} \cdot{ }^{\circ} \mathrm{C}\right) ; \mathrm{k}$-thermal conductivity, $\mathrm{W} /\left(\mathrm{m} \cdot{ }^{\circ} \mathrm{C}\right) ; \mathrm{L}$-length, $\mathrm{m} ; \mathrm{m}$-mass flow rate, $\mathrm{kg} / \mathrm{s}$; Nu -Nusselt number; $\mathrm{Q}$-heat flow rate, $\mathrm{W}$; Pr -Prandtl number; Re - Reynolds number; $\mathrm{t}$-temperature, ${ }^{\circ} \mathrm{C}$; $\mathrm{U}$-overall heat transfer coefficient, $\mathrm{W} /\left(\mathrm{m}^{2} \cdot{ }^{\circ} \mathrm{C}\right)$.

\section{Subscripts}

1 -inner tube/heat transfer between the inner two tubes;

2 -intermediate tube/inner annulus/heat transfer between the outer two tubes; 3 -outer tube/outer annulus; C -cold fluid; c -characteristic; ef -effective; $\mathrm{H}$-hot fluid; $\mathrm{h}$ - hydraulic; i -inner; in - inlet; Im -logarithmic mean; 0 -outer; out -outlet; w -wall; t-heated.

\section{Greek letters}

$\Delta$-difference; $\rho$-density, $\mathrm{kg} / \mathrm{m}^{3}$.

\section{References}

1.ZURITZ, C., J. Food Process Eng., 12, no. 2, 1990, p. 113 2.SATYANARAYANA, Ch. V. V., DATTA, A. K., MISHRA, B. P., J. Food Process Eng., 26, no. 3, 1995, p. 379.

3.UNAL, A., Int. Commun. Heat Mass, 25, no. 7, 1998, p. 949. 4.SAHOO, P. K., ANSARI, Md. I. A., DATTA, A. K., J. Food Eng., 58, no. 3, 2003, p. 211.

5.BATMAZ, E., SANDEEP, K. P., Heat Mass Transfer, 41, no. 3, 2005, p. 271.

6.PEIGNE, P., INARD, C., DRUETTE, L., Energies, 6, no. 1, 2013, p. 351. 7.BOULTIF, N., BOUGRIOU, C., Heat Mass Transfer, 53, no. 3, 2017, p. 849.

8.TOUATIT, A., BOUGRIOU, C, IJHT, 36, no. 1, 2018, p. 367.

9.RADULESCU, S., NEGOITA, L. I., ONUTU, I., Rev. Chim. (Bucharest), 63, no. 8, 2012, p. 820.

10.RADULESCU, S., NEGOITA, L. I., ONUTU, I., Rev. Chim. (Bucharest), 66, no. 1, 2015, p. 83.

11.PATRASCIOIU, C., RADULESCU, S., Heat Mass Transfer, 51, no. 1, 2015, p. 59.

12.SERTH, R. W., Process Heat Transfer. Principles and Applications, Elsevier Academic Press, U.S.A., 2007, p. 53-55.

13.LIENHARD, J. H. IV, LIENHARD, J. H. V, A Heat Transfer Textbook, 4th ed., Phlogiston Press, Cambridge, Massachusetts, 2017, p. 353.

Manuscript received: 17.08.2018 